\title{
ANALISIS SISTEM DRAINASE UNTUK PENANGANAN GENANGAN DI KECAMATAN MAGETAN BAGIAN UTARA
}

\author{
1) Mamok Suprapto, ${ }^{2)}$ Adi Yusuf M, ${ }^{3)}$ Agelbilal Seretora Prilbista \\ 1),2)Fakultas Teknik, Program Studi Teknik Sipil, Universitas Sebelas Maret, \\ 3)Mahasiswa Program S1, Teknik Sipil, Universitas Sebelas Maret, \\ Jl. Ir. Sutami 36A, Surakarta 57126; Telp. 0271-634524 \\ Email : seretoraprilbista@gmail.com
}

\begin{abstract}
Puddle during rainy season results in loss in many aspects. For the puddle to be handled effectively, a comprehensive analysis on drainage system is required in order to be used as the basis to determine the puddle bandling. To analyze the capacity of drainage system existing in accommodating the rain flow rate, simulation was used with software SWMM (Storm Water Management Model). The concept of handling was selected through simulation of drainage channel capacity in order to accommodate the planned flow rate. The result of simulation showed that the capacity of existing drainage channel was fairly good despite 5 channels exceeding the capacity of flow rate: C01, C09, C25, C26, and C38. Those five channels were overloaded for 1 hour during the flow rate peak occurring in the 2nd hour. The concept of repairing was conducted by means of increasing the capacity of drainage channel by increasing the channel's depth and width. Consequently, the increasing capacity of C25 and C26 channels resulted in the overflow in C27 channel, so that 6 channels required an increase in channel capacity.
\end{abstract}

Keywords: drainage, repairing concept, Storm Water Management Model

\begin{abstract}
Abstrak
Genangan pada saat musim penghujan menyebabkan kerugian di berbagai aspek. Agar penanganan dapat dilakukan secara efektif maka diperlukan analisis sistem drainase secara menyeluruh yang kemudian akan digunakan sebagai dasar penetuan penanganan genangan. Untuk menganalisis kapasitas sistem drainase eksisting dalam menampung debit hujan digunakan simulasi dengan software SWMM (Storm Water Management Model). Pemilihan konsep penanganan didapatkan melalui simulasi ulang kapasitas saluran drainase agar dapat menampung debit rencana. Berdasarkan hasil simulasi menunjukkan kapasitas saluran drainase eksisting cukup baik namum terdapat 5 saluran yang melebihi daya tampung debit aliran yaitu C01, C09, C25, C26 dan C38. Kelima saluran tersebut mengalami kelebihan kapasitas selama 1 jam pada saat puncak debit yang terjadi pada jam ke 2. Konsep perbaikan yang dilakukan berupa penambahan kapasitas saluran drainase dengan cara penambahan lebar dan kedalaman saluran. Konsekuensi dari penambahan kapasitas pada saluran C25 dan C26 menyebabkan meluapnya saluran C27. Sehingga terdapat 6 saluran yang memerlukan penambahan kapasitas saluran
\end{abstract}

Kata kunci : drainase, konsep perbaikan, Storm Water Management Model

\section{PENDAHULUAN}

Kabupaten Magetan setiap tahunnaya selalu mengalami permasalahan genangan saat musim penghujan. Salah satu Kecamatan di Kabupaten Magetan, yaitu Kecamatan Magetan khususnya bagian Utara sering mengalami permasalahan genangan yang menimbulkan karugian ekonomi. Untuk mengatasi permasalahan genangan yang terjadi, maka diperlukan kajian sistem drainase secara menyeluruh pada saluran yang terpengaruh genangan. Hasil kajian tersebut diharapkan dapat digunakan untuk membuat konsep penanganan masalah genangan yang tepat sesuai dengan kondisi lapangan. Untuk mengetahui kemampuan drainase eksisting digunakan simulasi pemodelan dengan software SWMM (Storm Water Management Model). Konsep perbaikan didapat dengan simulasi ulang kapasitas sistem drainase agar dapat menampung debit rencana

\section{TINJAUAN PUSTAKA}

\section{Periode Ulang dan Analisis Frekuensi}

Hujan rancangan dihitung dengan periode ulang tertentu yang diperoleh dari analisis frekuensi. Periode ulang merupakan waktu dimana hujan dengan besaran waktu tertentu akan disamai atau dilampui sekali dalam jangka 
waktu tertentu (Bambang Triatmojo, 2009). Tujuan analisis frekuensi mencari hubungan antara besarnya kejadian ekstrim terhadap frekuensi kejadian melalui penerapan distribusi (Suripin, 2004).

Ada 4 metode yang digunakan dalam analisis frekuensi yaitu Distribusi Normal, Distribusi Log Normal, Distribusi Gumbel, dan Distribusi Log Pearson III (Bambang Triatmojo, 2009). Parameter statistik dasar yang digunakan adalah nilai rata-rata $(\mathrm{X})$, standar deviasi (sd), Koefisien Skewness (Cs), Koefisien Variasi (Cv) dan Koefisien Kurtosis (Ck)

Untuk menguji apakah jenis distribusi yang dipilih sesuai dengan data yang ada yaitu dengan uji Chi-Kuadrat dan Smirnov-Kolmogorov (Bambang Triatmojo, 2009) sebagai berikut:

\section{Uji Chi Kuadrat}

Uji Chi-Kuadrat mengunakan parameter $X^{2}$ dapat dihitung dengan rumus: $X^{2}=\sum_{i=1}^{N} \frac{\left(O_{f}-E_{f}\right)^{2}}{E_{i}}$

Keterangan:

$$
\begin{array}{ll}
X^{2} & =\text { Parameter Chi-Kuadrat terhitung } \\
\mathrm{N} & =\text { Jumlah Sub Kelompok dalam satu grup } \\
\mathrm{O}_{\mathrm{f}} & =\text { Frekuensi yang terbaca pada kelas yang sama } \\
\mathrm{E}_{\mathrm{f}} & =\text { Frekuensi yang diharapkan sesuai dengan pembagian kelas }
\end{array}
$$

\section{Uji Smirnov-Kolmogorov}

Uji ini sering juga disebut juga uji kecocokan non parametik, karena pengujiannya dengan memperhatikan kurva dan penggambaran data pada kertas probabilitas. Apabila nilai Dmaksimum lebih kecil dari Do, maka distribusi teoritis yang digunakan untuk menentukan persamaan distribusi dapat diterima.

\section{Intensitas Hujan}

Intensitas hujan adalah tinggi atau kedalaman air persatuan waktu (M. Rizal Z dkk, 2016). Apabila data hujan yang diketahui hanya data hujan harian maka digunakan Metode Mononobe (Suripin, 2004) dirumuskan sebagai berikut:

$I=\frac{R_{24}}{24} \times\left(\frac{24}{t}\right)^{2 / 3}$

Dengan:

$$
\begin{array}{ll}
\mathrm{I} & =\text { Intensitas hujan (mm/jam). } \\
\mathrm{t} & =\text { Lama hujan (jam). } \\
\mathrm{R}_{24} & =\text { Curah hujan maksimum harian dalam } 24 \text { jam }(\mathrm{mm}) .
\end{array}
$$

\section{Storm Water Management Model (SWMM)}

Untuk menghitung debit rencana pada saluran drainase dan kapasitas saluran mengunakan alat bantu berupa software EPA SWMM 5.1. SWMM (Storm Water Management Model) adalah model simulasi dinamis hubungan antara curah hujan dan limpasan yang dikembangkan oleh U.S. Environmental Protection Agency (EPA). Pemodelan dengan SWMM berdasarkan berbagai proses hidrologi seperti curah hujan dengan variasi waktu, evaporasi pada permukaan air, curah hujan pada daerah tampungan dan infiltrasi dari curah hujan yang masuk ke lapisan tanah tak jenuh air yang memperhatikan limpasan dan sistem drainase.

\section{Konsep Perbaikan Saluran}

Konsep perbaikan saluran drainase didasarkan pada pendekatan prinsip dasar penanggulangan genangan, yaitu kemampuan saluran dalam menampung debit rencana yang terjadi. Perencanaan ulang saluran drainase dibutuhkan sehingga saluran drainase diharapkan mampu menampung kelebihan debit yang tidak mampu ditampung saluran eksisting. Peningkatan kapasitas pada saluran drainse dapat dilakukan dengan cara penambahan pada lebar saluran, kedalaman saluran atau kombinasi dari keduanya

\section{METODE PENELITIAN}

Lokasi penelitian ini dilakukan di Kecamatan Magetan Bagian Utara, Kabupaten Magetan. Pemilihan lokasi ini dilakukan karena di lokasi ini setiap tahunnya pada musim penghujan selalu terjadi genangan yang menimbulkan kerugian ekonomi. 
Tahapan pertama dari penelitian ini melakukan pengumpulan data primer dan sekunder. Selanjutnya dilakukan analisis data yang meliputi analisis debit saluran dan kapasitas saluran drainase eksisting dengan bantuan software SWMM. Penanganan genangan didapatkan melalui simulasi ulang analisis kapasitas saluran drainase menggunakan software SWMM agar dapat menampung debit rencana dengan penambahan kapasitas saluran dengan cara penambahan lebar dan penambahan kedalaman saluran.

\section{HASIL DAN PEMBAHASAN}

\section{Hujan Harian Maksimum}

Data hujan harian maksimum menggunakan data dari dua stasiun penakar hujan yaitu: Stasiun Jejeruk dan Slagreng dengan periode pengamatan data curah hujan yang digunakan selama 10 (sepuluh) tahun dari tahun 2006 sampai 2015. Data hujan pada semua stasiun hujan tersebut dapat digunakan berdasarkan uji kepanggahan dengan metode RAPS dan dinyatakan panggah

\section{Hujan Rancangan}

Penetuan metode analisis frekuensi dihitung menggunakan 4 metode yaitu metode normal, gumbel, Log normal, dan log pearson III. Dari hasil uji dengan Uji Chi Kuadrat Dan Uji Smirnov-Kolmorov semua metode analisis frekuensi dapat diterima, sehingga dipilih metode yang menghasilkan nilai $\mathrm{X}_{\mathrm{h}}{ }^{2}$ dari uji Chi Kuadrat dan Dmaks dari Uji Smirnov-Kolmorov yang terkecil yaitu metode Log Normal. Hasil Hujan Rancangan metode Log Normal ditampilkan pada Tabel 1

Tabel 1 Hasil Uji dengan Uji Chi Kuadrat dan Uji Smirnov-Kolmogorov

\begin{tabular}{lrrr}
\hline \multicolumn{1}{c}{ Kala Ulang $(\mathrm{T})$} & $\mathrm{K}_{\mathrm{T}}$ & $\mathrm{Log} \mathrm{X}_{\mathrm{t}}$ & $\mathrm{X}_{\mathrm{T}}(\mathrm{mm})$ \\
\hline 1,01 & $-2,33$ & 1,75 & 56 \\
\hline 2 & 0,00 & 2,00 & 99 \\
\hline 5 & 0,84 & 2,09 & 122 \\
\hline 10 & 1,28 & 2,13 & 136 \\
\hline 25 & 1,71 & 2,18 & 152 \\
\hline
\end{tabular}

\section{Intensitas Hujan Rancangan}

Karena data hujan jam-jam tidak tersedia maka hujan jam-jam diturunkan dari hujan harian berdasarkan perkiraan lama hujan. waktu konsentrasi aliran diperoleh menggunakan beberapa metode seperti metode Kirpich, metode FAA, dan metode Kerby. Metode waktu konsentrasi dipilih berdasarkan hasil perhitungan yang menghasilkan waktu konsentrasi terkecil yaitu metode Kirpich yang menghasilkan watu konsentrasi 4 jam. Perhitungan intensitas hujan rancangan menggunakan metode Mononobe. Hasil perhitungan intensitas hujan rancangan ditampilkan pada Tabel 2

Tabel 2 Intensitas Hujan Rancangan

\begin{tabular}{crrrrr}
\hline Periode Ulang (tahun) & \multirow{2}{*}{ Rt } & \multicolumn{5}{l}{ Intensitas Hujan (I) (mm/jam) } \\
\cline { 3 - 6 } & & \multicolumn{6}{c}{1} & 2 & 3 & 4 \\
\hline 1,01 & 56 & 35 & 9 & 6 & 5 \\
\hline 2 & 99 & 63 & 16 & 11 & 9 \\
\hline 5 & 122 & 77 & 20 & 14 & 11 \\
\hline 10 & 136 & 86 & 22 & 16 & 12 \\
\hline 25 & 152 & 96 & 25 & 17 & 14 \\
\hline
\end{tabular}

Simulasi Kapasitas Saluran Drainase Eksisting dengan EPA SWMM Pembuatan Skema Jaringan Drainase 
Sistem drainase yang ada dimodelkan ke dalam software SWMM. Terdapat 44 Subcatchment Area, 38 Junction, 38 Conduit, dan 6 Outfall. Model skema jaringan drainase ditampilkan dalam Gambar 1

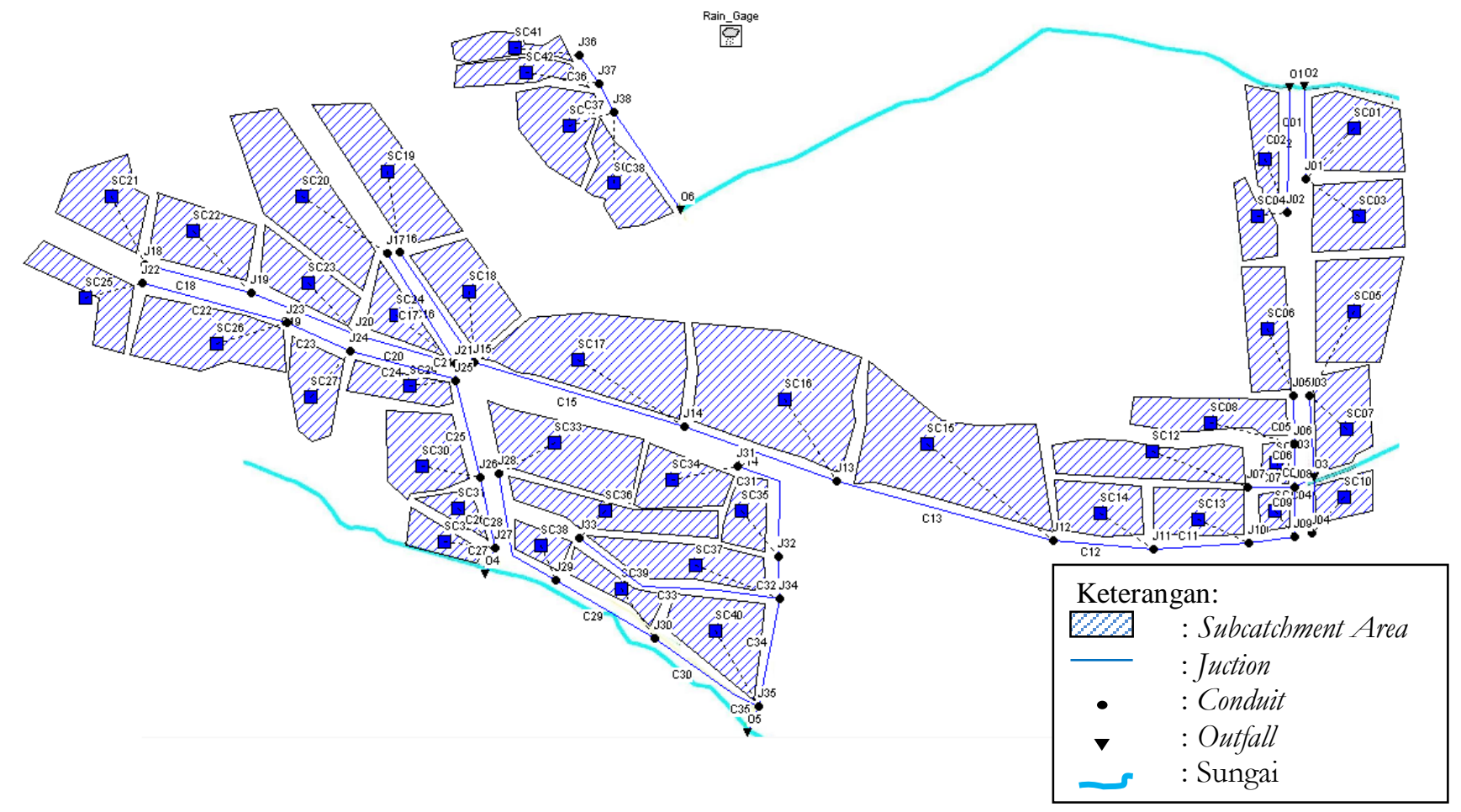

Gambar 1 Skema Jaringan Drainase

\section{Hasil Simulasi}

Dengan mengunakan model jaringan dan time series mengunakan waktu konsentrasi 4 jam, dengan intensitas hujan dengan kala ulang 5 tahun menghasilkan hasil kualitas simulasi yang cukup baik. Dimana continuity error untuk limpasan dan penelusuran aliran masing- masing sebesar - $-0,25 \%$ dan $-0,61 \%$. Kualitas dikatakan kurang baik jika continuity error $>10 \%$. Hasil simulasi ditampilkan dalam Gambar 2

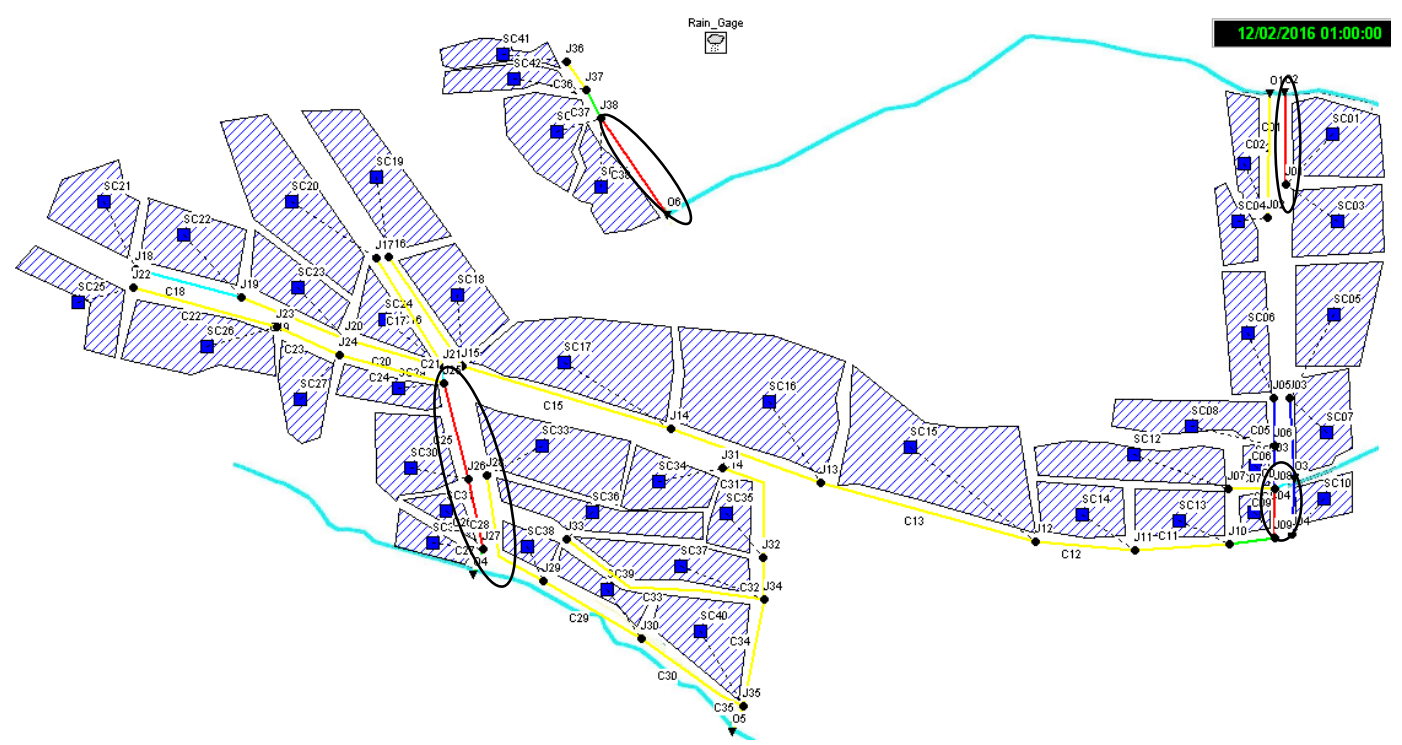

Gambar 2 Kondisi Saluran Hasil Simulasi

Saluran yang tergenang ditunjukkan dengan warna merah. Berdasarkan hasil simulasi terdapat lima (5) saluran yang tergenang. Saluran tersebut adalah saluran C01, C09, C25,C26 dan C38. Terkait dengan itu, maka dilakukan 
penambahan kapasitas saluran pada lima saluran tersebut. Hasil simulasi saluran yang tergenang lebih jelasnya dapat dilihat pada Tabel 3

Tabel 3 Hasil Simulasi Pada Saluran yang Tergenang

\begin{tabular}{rrrrrl}
\hline $\begin{array}{c}\text { Nama } \\
\text { Saluran }\end{array}$ & $\begin{array}{c}\text { Lama Aliran } \\
\text { Maksimal (Jam) }\end{array}$ & $\begin{array}{c}\text { Kecepatan } \\
\text { Maksimal }(\mathrm{m} / \mathrm{s})\end{array}$ & $\begin{array}{c}\text { Kedalaman } \\
\text { Maksimal }\end{array}$ & $\begin{array}{c}\text { Keterangan } \\
\text { Warna }\end{array}$ & Keterangan \\
\hline C01 & $1: 24$ & 2.38 & 1 & Merah & Meluap \\
\hline C09 & $2: 44$ & 2.1 & 1 & Merah & Meluap \\
\hline C25 & $1: 17$ & 2.81 & 1 & Merah & Meluap \\
\hline C26 & $1: 23$ & 3.33 & 1 & Merah & Meluap \\
\hline C38 & $1: 32$ & 2.94 & 1 & Merah & Meluap \\
\hline
\end{tabular}

\section{Konsep Perbaikan Saluran Drainase \\ Peningkatan Kapasitas Terkait Outlet}

Dari hasil simulasi terdapat 2 saluran terkait outlet yang memerlukan penambahan kapasitas yaitu saluran C01 dan C38. Pada saluran terkait outlet, lebih mengutamakan pemanbahan lebar saluran. Untuk penambahan kedalaman harus memperhatikan muka air banjir maksimal. Penambahan lebar terjadi pada kedua saluran. Pengecualian untuk saluran C38 penambahan kedalaman saluran dapat dilakukan karena ketinggian outlet masih berada di atas muka banjir maksimal saluran outlet. Perubahan lebar dan kedalaman pada saluran terkait outlet ditamplkan pada Tabel 4

Tabel 4 Perubahan Lebar Saluran Pada Saluran Terkait Outlet

\begin{tabular}{lrrrr}
\hline Nama Saluran & Lebar Awal $(\mathrm{m})$ & Lebar Rencana $(\mathrm{m})$ & Kedalaman Awal $(\mathrm{m})$ & Kedalaman Rencana $(\mathrm{m})$ \\
\hline C01 & 0,30 & 0,50 & 0,70 & 0,70 \\
\hline C38 & 0,80 & 0,90 & 0,40 & 0,45 \\
\hline
\end{tabular}

\section{Peningkatan Kapasitas Saluran yang Terkait dengan Sistem}

Perbaikan saluran drainase yang terkait dengan sistem dengan penambahan dimensi saluran pada bangunan outlet masih belum mengurangi limpasan yang terjadi pada saluran yang melimpas. Berdasarkan hasil simulasi yang dilakukan maka dilakukan perbaikan saluran berupa penambahan lebar dan kedalaman saluran. Perubahan kapasitas pada C25 dan C26 ternyata mengakibatkan saluran C27 meluap, sehingga saluran C27 memerlukan perbaikan. Perubahan lebar dan kedalaman pada saluran terkait sistem yang ditampilkan dalam Tabel 5

Tabel 5 Perubahan Lebar dan Kedalaman Saluran Pada Saluran Terkait Sistem

\begin{tabular}{lrrrr}
\hline Nama Saluran & Lebar Awal (m) & Lebar Rencana (m) & Kedalaman Awal (m) & Kedalaman Rencana (m) \\
\hline C09 & 1,00 & 1,30 & 1,20 & 1,40 \\
\hline C25 & 0,75 & 1,10 & 0,65 & 1,00 \\
\hline C26 & 0,75 & 1,10 & 0,65 & 1,00 \\
\hline C27 & 0,75 & 1,00 & 0,65 & 0,65 \\
\hline
\end{tabular}

\section{Hasil Simulasi Setelah Perbaikan}

Data dimensi yang baru, kemudian diinput dan disimulasikan kembali ke model SWMM. Dari hasil simulasi ulang dapat dilihat sudah tidak ada saluran yang meluap. Kondisi saluran dengan perubahan dimensi ditampilkan dalam Gambar 3. 


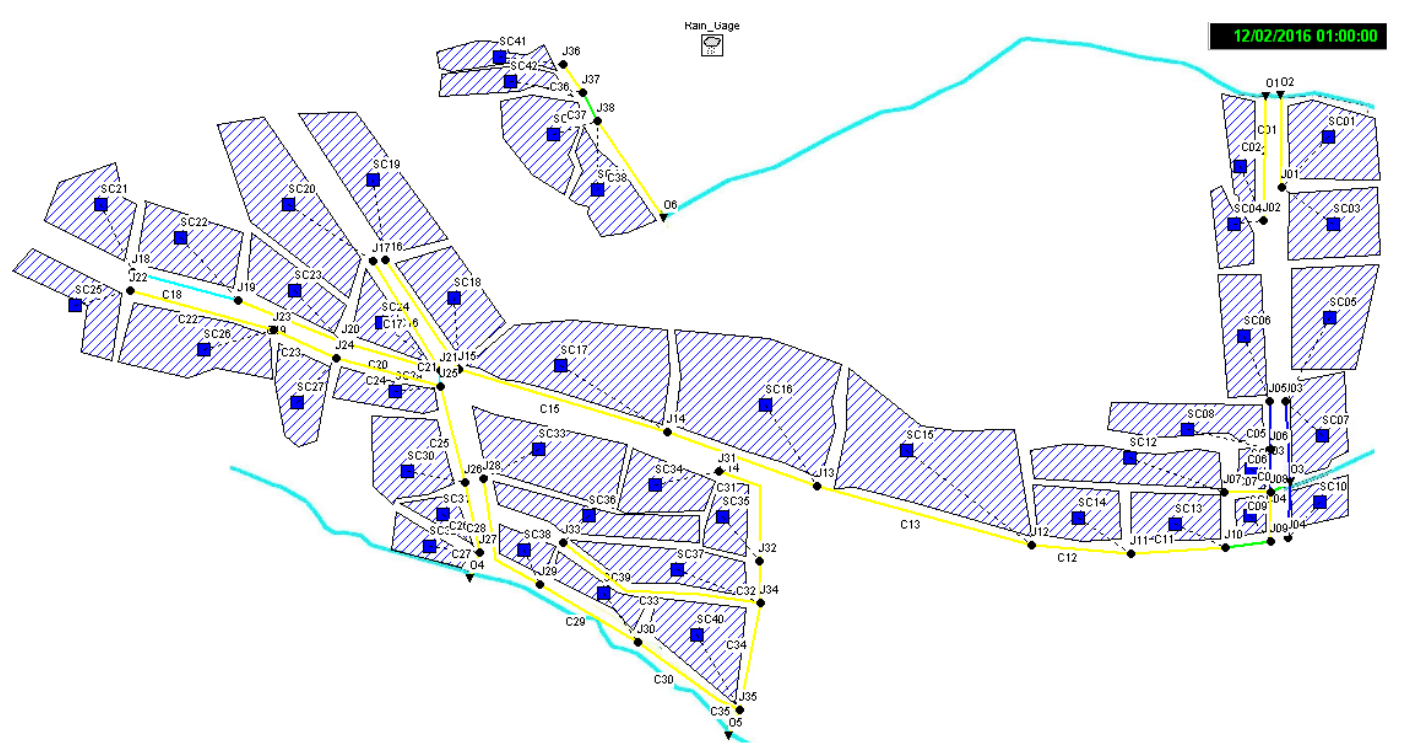

Gambar 3 Kondisi Saluran Setelah Dilakukan Perubahan Dimensi

Hasil simulasi saluran yang tergenang setelah dilakukan perbaikan lebih jelasnya dapat dilihat pada Tabel 6

Tabel 6 Hasil Simulasi Pada Saluran yang Tergenang Setelah Perbaikan

\begin{tabular}{lrrrll}
\hline $\begin{array}{c}\text { Nama } \\
\text { Saluran }\end{array}$ & $\begin{array}{c}\text { Lama Aliran } \\
\text { Maksimal (Jam) }\end{array}$ & $\begin{array}{c}\text { Kecepatan } \\
\text { Maksimal }(\mathrm{m} / \mathrm{s})\end{array}$ & $\begin{array}{c}\text { Kedalaman } \\
\text { Maksimal }\end{array}$ & $\begin{array}{c}\text { Keterangan } \\
\text { Warna }\end{array}$ & Keterangan \\
\hline C01 & $2: 00$ & 2.95 & 0.86 & Kuning & Tidak Meluap \\
\hline C09 & $2: 00$ & 2.45 & 0.99 & Kuning & Tidak Meluap \\
\hline C25 & $1: 18$ & 2.81 & 0.90 & Kuning & Tidak Meluap \\
\hline C26 & $1: 24$ & 3.33 & 0.84 & Kuning & Tidak Meluap \\
\hline C27 & $2: 00$ & 6.37 & 0.61 & Hijau & Tidak Meluap \\
\hline C38 & $1: 34$ & 2.94 & 0.89 & Kuning & Tidak Meluap \\
\hline
\end{tabular}

Penambahan kedalaman sudah memperhatikan elevasi muka air banjir pada saluran outlet. Peningkatan kapasitas saluran drainase dengan penambahan lebar saluran hanya menimbulkan pengurangan pada bahu jalan hal itu dapat dilihat penambahan lebar saluran lebih kecil daripada lebar bahu jalan. Sehingga lebar jalan tidak mengalami pengurangan. Dampak dari penambahan lebar saluran dapat dilihat pada Tabel 7

Tabel 7 Dampak Penambahan Lebar Saluran

\begin{tabular}{lrrr}
\hline $\begin{array}{c}\text { Nama } \\
\text { Saluran }\end{array}$ & $\begin{array}{c}\text { Lebar Jalan } \\
(\mathrm{cm})\end{array}$ & $\begin{array}{c}\text { Lebar Bahu } \\
\text { Jalan }(\mathrm{cm})\end{array}$ & $\begin{array}{c}\text { Penambahan Lebar } \\
\text { Saluran }(\mathrm{cm})\end{array}$ \\
\hline C01 & 1500 & 100 & 20 \\
\hline C09 & 1500 & 30 & 20 \\
\hline C25 & 800 & 100 & 35 \\
\hline C26 & 800 & 100 & 35 \\
\hline C27 & 800 & 100 & 25 \\
\hline C38 & 400 & 30 & 10 \\
\hline
\end{tabular}

\section{SIMPULAN}

Berdasarkan pengolahan dan analisis data pada penelitian ini, dapat ditarik kesimpulan sebagai berikut: 
1 Kapasitas drainase eksisting cukup baik, namum terdapat 5 saluran yang tidak mampu menampung debit hujan. Saluran tersebut adalah saluran C01, C09, C25, C26 dan C38. Kelima saluran tersebut perlu dilakukan penambahan kapasitas saluran.

2 Konsep perbaikan saluran drainase pada daerah genangan adalah dengan meningkatkan kapasitas saluran dengan cara penambahan lebar, penambahan kedalaman serta gabungan dari keduanya. Perbaikan pada saluran terkait sistem menyebabkan saluran C27 meluap, sehingga saluran C27 memerlukan penambahan kapasitas saluran. Desain ulang dimensi saluran pada masing-masing saluran sebagai berikut:

a) Saluran C01 dengan lebar saluran 0,50 $\mathrm{m}$ dan kedalaman saluran 0,70 $\mathrm{m}$

b) Saluran C09 dengan lebar saluran 1,30 m dan kedalaman saluran 1,40 m

c) Saluran C25 dengan lebar saluran 1,10 m dan kedalaman saluran 1,00 m

d) Saluran C26 dengan lebar saluran 1,10 m dan kedalaman saluran 1,00 m

e) Saluran C27 dengan lebar saluran 1,00 m dan kedalaman saluran $0.65 \mathrm{~m}$

f) Saluran C38 dengan lebar saluran 0,90 $\mathrm{m}$ dan kedalaman saluran 0,45 m

Dampak dari penambahan lebar saluran hanya akan memperkecil lebar bahu jalan, sementara labar jalan tidak mengalami pengurangan

\section{REFERENSI}

Bambang Triatmodjo. 2009. Hidrologi Terapan. Beta Offset. Yogyakarta

Deasy Natalie dan Erlangga Hartawan. 2008. Hubungan Antara Kapasitas Kolam Retasi Dengan Debit Banjir (Studi Kasus Daerah Aliran Sungai Beringin). Skripsi. Semarang: Fakultas Teknik Program Studi Teknik Sipil, Universitas Katolik Soegijapranata.

Desyi Astuti, Siswanto, dan Imam Suprayogi. 2016. Analisi Kolam Retensi Sebagai Pengendalian Genangan di Kecamatan Paynng Sekaki. Jurnal. Pekanbaru: Fakultas Teknik Sipil Jurusan Teknik Sipil, Universitas Riau.

Edwin Prasetya Kurniawan. 2016. Prioritas Perbaikan Saluran Drainase Dengan Metode Analytic Network Process (ANP) Di Kelurahan Kadipiro Bagian Barat. Skripsi. Surakarta: Fakultas Teknik Program Studi Teknik Sipil, Universitas Sebelas Maret.

Emir Aditya. 2015. Evaluasi Saluran Dengan Model EPA SWMM 5.1 Di Perumahan Griya Telaga Permai Depok Jawa Barat. Skripsi. Bogor: Fakultas Teknologi Pertanian Departemen Teknik Sipil Dan Lingkungan, Institut Pertanian Bogor.

Hsu, Ming-Hsi., Chen, Albert S dan Chang, Tsang-Jung. 2000. Inundation Simulation For Urban Drainage Basin With Storm Sewer System. Joutnal of Hydroly, 234(1-2), 21-37, DOI:10.1016/S0022-1694(00)00237.

M Rizal Zarkani, Bambang Sujatmoko, dan Rinaldi. 2016. Analisa Drainase Untuk Penanggulangan Banjir Menggunakan EPA SWMM (Studi Kasus: Perumahan Mutiara Witayu Kecamatan Rumbai Pekanbaru). Jurnal. Pekanbaru: Fakultas Teknik Sipil Jurusan Teknik Sipil, Universitas Riau.

Sri Hartono. 1993. Analisis Hidrologi. Gramedia Pustaka Utama. Jakarta.

Sri Surya Ningsih. 2013. Evaluasi Saluran Drainase Di Perumahan Cinta Kasib Cengkareng Dengan Menggunakan Model EPA SWMM 5.0. Skripsi. Bogor: Fakultas Teknologi Pertanian Departemen Teknik Sipil Dan Lingkungan, Institut Pertanian Bogor.

Suripin. 2004. Sistem Drainase Perkotaan yang Berkelanjutan. Andi. Yogyakarta.

Vikry Aditya Vidyanandha. 2016. Prioritas Perbaikan Saluran Drainase Dengan Metode Analytic Network Process (ANP) Di Kelurahan Kadipiro Bagian Timur. Skripsi. Surakarta: Fakultas Teknik Program Studi Teknik Sipil,Universitas Sebelas Maret. 